OPEN ACCESS

Edited by:

Alexander Arthur Theodore Johnson,

University of Melbourne, Australia

Reviewed by:

Giacomo Cocetta,

Università degli Studi di Milano, Italy

Wricha Tyagi,

Central Agricultural University, India

*Correspondence:

Tomoko Nozoye

atom1210@mail.ecc.u-tokyo.ac.jp

Specialty section:

This article was submitted to

Plant Nutrition,

a section of the journal

Frontiers in Plant Science

Received: 03 December 2017

Accepted: 28 February 2018

Published: 27 March 2018

Citation:

Nozoye T (2018) The Nicotianamine Synthase Gene Is a Useful Candidate for Improving the Nutritional Qualities and Fe-Deficiency Tolerance of Various Crops.

Front. Plant Sci. 9:340. doi: 10.3389/fpls.2018.00340

\section{The Nicotianamine Synthase Gene Is a Useful Candidate for Improving the Nutritional Qualities and Fe-Deficiency Tolerance of Various Crops}

\author{
Tomoko Nozoye 1,2* \\ ${ }^{1}$ Center for Liberal Arts, Meiji Gakuin University, Kanagawa, Japan, ${ }^{2}$ Department of Global Agricultural Sciences, Graduate \\ School of Agricultural and Life Sciences, The University of Tokyo, Tokyo, Japan
}

With the global population predicted to grow by at least 25\% by the year 2050, the sustainable production of nutritious foods will be necessary for human health and the environment. Iron $(\mathrm{Fe})$ is an essential nutrient for both plants and humans. Fe is poorly soluble, especially at high $\mathrm{pH}$ levels, at which it is difficult for living organisms to accumulate sufficient Fe. In plants, Fe deficiency leads to low yield and poor nutritional quality, as it significantly affects chlorophyll synthesis. Fe deficiency is a worldwide agricultural problem that is especially serious in soils with a high $\mathrm{pH}$, such as calcareous soils, which comprise approximately $30 \%$ of cultivated soils worldwide. Genetic improvements in crops that can tolerate Fe deficiency will be required to meet the demands for crop production and could ultimately contribute to the amelioration of global warming. Nicotianamine (NA) is an Fe chelator in plants that is involved in metal translocation in the plant body. In mammals, NA inhibits angiotensin I-converting enzyme, which plays a key role in blood pressure control. It was recently shown that the enhancement of NA production using nicotianamine synthase is useful for increasing not only NA but also Fe and Zn levels in crops such as rice, soybean, and sweet potato. Additionally, these plants showed Fe-deficiency tolerance in calcareous soil. These results suggested that NAS overexpression simultaneously improves food quality and increases plant production. This review summarizes progress in generating crops overexpressing NAS.

Keywords: calcareous soil, iron (Fe), zinc (Zn), Fe deficiency, nicotianamine (NA)

\section{INCREASING Fe DEFICIENCY TOLERANCE COULD CONTRIBUTE TO FOOD SECURITY AND AMELIORATE GLOBAL WARMING}

Iron $(\mathrm{Fe})$ is an essential nutrient for virtually all living organisms. Under aerobic conditions, $\mathrm{Fe}$ is oxidized to $\mathrm{Fe}(\mathrm{III})$ compounds, and their solubility in water is poor. Therefore, most Fe is not available to plants, although mineral soils contain $6 \% \mathrm{Fe}$ by weight. Plants suffering $\mathrm{Fe}$ deficiency show leaf chlorosis, and their yield and nutritional quality are impaired dramatically 
(Marschner, 1995). This problem is exacerbated in soils with a high $\mathrm{pH}$, such as calcareous soils, and is one of the major problems for crop production. Calcareous soils comprise approximately $30 \%$ of the cultivated soils worldwide (Chen and Barak, 1982). As the world population continues to increase, it is predicted that we will need 1.5 times more food in 2050 (High Level Expert Forum - How to Feed the World in 2050, 2009). It will be necessary to increase food production to meet this demand. However, the recent increase in atmospheric $\mathrm{CO}_{2}$ levels is causing climate change, and it will be difficult to expand the area occupied by cultivated land by removing forests, which already contribute $2 \%$ of the $\mathrm{CO}_{2}$ emissions (Intergovenmental Panel on Climate Change [IPCC], 2007). Problem soils, including calcareous soil, comprise $67 \%$ of the land globally (Food and Agriculture Organization of the United Nations). Improvements in plant growth in calcareous soils have great potential to increase the production of plant biomass and reduce atmospheric $\mathrm{CO}_{2}$ levels, which will ultimately contribute to ameliorating global warming (Conway, 2012; Schroeder et al., 2013). In addition, Fe is necessary for human health, and its deficiency causes anemia, an easily identified disease that is a serious health problem, especially in developing countries (Welch and Graham, 2004). Ultimately, Fe in the human diet comes from plant uptake from the soil. Therefore, biofortification, i.e., increasing the Fe level in food plants, would improve human health. Appropriate target levels of Fe might differ according to the crop and target countries, as food cultures differ. For a rice-based diet, the target concentration of Fe was estimated to be $14.5 \mu \mathrm{g} / \mathrm{g}$ dry weight (DW) in polished rice grains, which is more than twice the present amount in rice $(6 \mu \mathrm{g} / \mathrm{g} \mathrm{DW})$ (Hotz and McClafferty, 2007; Johnson et al., 2011). Therefore, genetically modified crops that can tolerate Fe deficiency while taking up sufficient Fe from calcareous soils would have a great impact on food security and contribute to ameliorating global warming.

\section{Fe ACQUISITION STRATEGIES IN PLANTS}

To acquire sparingly insoluble Fe from soil, plants have evolved two main strategies to acquire soil Fe (Marschner et al., 1986). Higher plants, not including graminaceous plants, which include soybean and sweet potato, are categorized as Strategy I plants, which reduce $\mathrm{Fe}$ (III) to $\mathrm{Fe}$ (II) by ferric-chelate reductases, and then take up $\mathrm{Fe}$ (II) via ferrous iron transporters IRT1 (Eide et al., 1996; Robinson et al., 1999; Vert et al., 2002). By contrast, graminaceous plants, including important staple crops such as rice, barley, and maize, are categorized as Strategy II plants, which produce and secrete Fe(III) chelators called mugineic acid family phytosiderophores (MAs) from their roots via the TOM1 transporter (Nozoye et al., 2011, 2013) and solubilize sparingly soluble Fe(III) in the rhizosphere (Takagi, 1976).

Nicotianamine (NA) is a non-proteinogenic amino acid that was first found in tobacco (Noma et al., 1971). NA chelates many metal cations, including $\mathrm{Fe}$, zinc $(\mathrm{Zn})$, copper $(\mathrm{Cu})$, and manganese (Mn) (Beneš et al., 1983; Murakami et al., 1989; von Wirén et al., 1999). NA exists in all plants examined so far, including Strategy I and II plants (Hell and Stephan, 2003; Takahashi et al., 2003; Schuler et al., 2012), and plays an important role in the internal transport of metal nutrients (Mori et al., 1991; Kawai et al., 2001; Hell and Stephan, 2003; Takahashi et al., 2003; Suzuki et al., 2006; Schuler et al., 2012). In graminaceous plants, NA also serves as an intermediate for the biosynthesis of MAs (Takagi, 1976; Mori and Nishizawa, 1987; Shojima et al., 1990). NA synthase (NAS) converts three molecules of $S$-adenosyl methionine into NA (Shojima et al., 1989, 1990; Higuchi et al., 1995). NAS genes were first isolated from barley and have subsequently been cloned from several plants species, including Arabidopsis, barley, rice, and maize (Herbik et al., 1999; Higuchi et al., 1999, 2001; Suzuki et al., 1999; Mizuno et al., 2003). Rice possesses three members: OsNAS1-3. OsNAS1, and OsNAS2 are mainly expressed in Fe-deficient roots and shoots, whereas OsNAS3 is also expressed in Fe-sufficient shoots (Inoue et al., 2003). It was suggested that all three have important roles in NA production under Fe-deficient conditions, although their roles might differ slightly.

\section{NICOTIANAMINE IS ALSO AN ATTRACTIVE FUNCTIONAL COMPONENT IN HUMAN HEALTH}

In mammals, NA inhibits angiotensin I-converting enzyme (ACE), which plays a key role in blood pressure control (Kinoshita et al., 1993). ACE plays a role in the renin-angiotensin system in the maintenance of blood pressure and fluids, as well as electrolyte homeostasis (Re, 2004). ACE inhibitors are widely used as antihypertensive agents (Chirumamilla et al., 2001; Re, 2004) The oral administration of NA causes ACE inhibitory activity in vitro and antihypertensive effects in spontaneously hypertensive rats; moreover, the strength of ACE inhibition is correlated with NA content (Izawa et al., 2008). The inhibitory activity of NA against ACE is very strong (Kinoshita et al., 1993; Kataoka, 2005). Almost all vegetables contain more than $44 \mu \mathrm{g} / \mathrm{g}$ DW NA, which has the ability to inhibit ACE activity by more than 60-70\% (Izawa and Aoyagi, 2012). In addition, NA from pumpkin not only improves hypertension, but also long-term memory function (Takada, 2011). In fact, brain-penetrating ACE inhibitors such as captopril reduce the incidence of Alzheimer's disease in elderly hypertensive patients (Ohrui et al., 2004). Therefore, increased intake of NA through the diet could be effective for primary prophylaxis of hypertension and Alzheimer's disease.

\section{TRANSGENIC APPROACH TO INCREASING NA IN PLANTS}

Several reports have described transgenic plants generated by introducing the NAS gene (Table 1). The concentration of endogenous NA differs among crops (Izawa et al., 2008; 


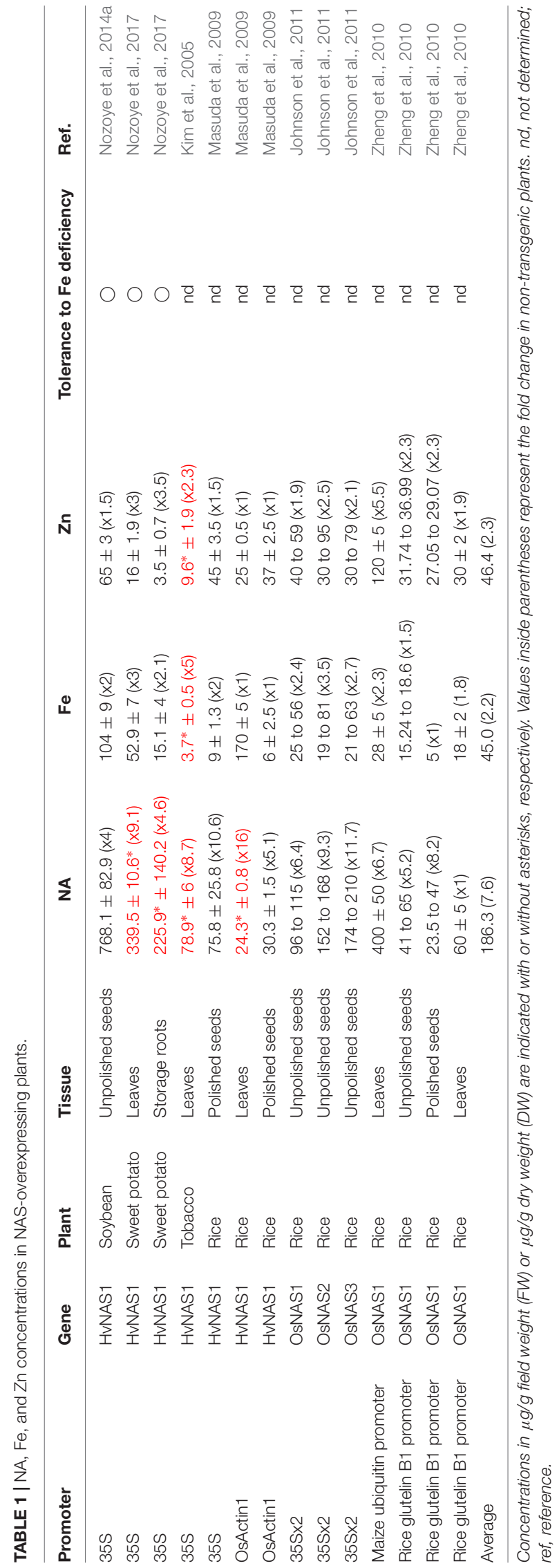

Izawa and Aoyagi, 2012). The antihypertensive effect of NA was first identified in soybean (Kinoshita et al., 1993), which contains the highest amount of NA among the crops examined thus far (Izawa et al., 2008). In agreement with the endogenous NA level, the NA concentration in transgenic soybean was highest among the HvNAS1-overexpressing plants. The NA concentration in the transgenic soybean was increased to $768.1 \mu \mathrm{g} / \mathrm{g}$ DW in the seeds under the control of the cauliflower mosaic virus (CaMV) 35S promoter, which was four times higher than in non-transgenic (NT) seeds (Nozoye et al., 2014a). In sweet potato, overexpression of HvNAS1 by the CaMV $35 \mathrm{~S}$ promoter increased the NA concentration to $339.5 \mu \mathrm{g} / \mathrm{g}$ fresh weight (FW) in the leaves and $225.9 \mu \mathrm{g} / \mathrm{g} \mathrm{FW}$ in the storage roots, which were 9.1 and 4.6 times higher, respectively, than in NT plants (Nozoye et al., 2017). In comparison, the NA concentration in HvNAS1-overexpressing tobacco (a dicot) by the CaMV $35 \mathrm{~S}$ promoter was $78.9 \mu \mathrm{g} / \mathrm{g}$ FW in the leaves, which was 8.7 times higher than in NT plants (Kim et al., 2005). It was suggested that NAS genes are separated into two clusters between Gramineae and dicots and that the NASs in soybean and sweet potato were most similar in the dicot cluster (Nozoye et al., 2017). The NASs in soybean and sweet potato might have high enzymatic activity and produce more NA. The endogenous NA concentrations also differed among the tissues in rice (Table 1). The NA concentrations in leaves tended to be higher than that in the seeds. Consistent with the endogenous NA levels, the NA concentrations in leaves were also higher than those in seeds in NAS-overexpressing rice plants. Overexpression of HvNAS1 by the CaMV $35 \mathrm{~S}$ promoter increased the NA concentration to $75.8 \mu \mathrm{g} / \mathrm{g}$ DW in the polished seeds, which was 10.6 times higher than in NT seeds (Masuda et al., 2009). Overexpression of HvNAS1 by the OsActin1 promoter increased the NA concentration to $30.3 \mu \mathrm{g} / \mathrm{g}$ DW in the polished seeds, which were 16 and 5.1 times higher, respectively, than in NT plants (Masuda et al., 2009). By overexpressing rice NAS genes (OsNAS1-3) in rice under the control of an enhanced CaMV $35 \mathrm{~S}$ promoter, the NA concentration in rice seeds increased to $210 \mu \mathrm{g} / \mathrm{g}$ DW, which was 9.3 times higher than in NT seeds (Johnson et al., 2011). In comparison, by overexpressing OsNAS1 in rice under the control of the maize ubiquitin promoter, the NA concentration in rice leaves increased to $400 \mu \mathrm{g} / \mathrm{g} \mathrm{DW}$, which was 6.7 times higher than in NT leaves (Zheng et al., 2010). Using seed-specific expression of OsNAS1 under the control of the rice glutelin promoter, the NA concentration in rice seeds increased to $65 \mu \mathrm{g} / \mathrm{g}$ DW, which was 5.2 times higher than in NT seeds (Zheng et al., 2010). This concentration was slightly lower than that in NAS-overexpressing rice seeds under the control of ubiquitous promoters. Additionally, in these plants, the NA concentration in shoots was not different from that in NT plants. These results suggest that it is possible to achieve a greater increase in NA in seeds by enhancing NA mobilization and translocation from leaves (and roots) to seeds. The average increase (fold change) in NA concentration was 7.6 and did not differ significantly among the crops, suggesting that the amount of endogenous NA is not a factor that limits the NA concentration. The combined enhancement of NAS and NA transporters could further elevate the NA level in the edible parts of the plant. 


\section{ENHANCEMENT OF NA INCREASED THE Fe AND Zn CONCENTRATIONS IN PLANTS}

Nicotianamine plays an important role in metal transport in the plant body. It was suggested that NA is involved in the translocation of Fe and $\mathrm{Zn}$ into seeds in rice, Arabidopsis, tomato, and tobacco (Higuchi et al., 1996; Takahashi et al., 2003; Kim et al., 2005; Masuda et al., 2008, 2009; Schuler et al., 2012). Fe is readily oxidized and precipitated in the apoplasm of both roots and shoots. Therefore, Fe uptake from the apoplasm is important for plant growth. In the Arabidopsis double IRT1 and Nramp1 mutant, Fe was precipitated and accumulated in the apoplast of the roots, while the Fe concentration in shoots was dramatically reduced compared with NT (Castaings et al., 2016). In NASoverexpressing plants, the $\mathrm{Fe}$ and $\mathrm{Zn}$ concentrations were also increased (Table 1). NA might be involved in the mobilization of $\mathrm{Fe}$ and $\mathrm{Zn}$ in the apoplasm. In the seeds of HvNAS1overexpressing soybean plants, the $\mathrm{Fe}$ and $\mathrm{Zn}$ concentrations increased to 110 and $65 \mu \mathrm{g} / \mathrm{g}$ DW, which were 2 and 1.45 times higher, respectively, than in NT plants (Nozoye et al., 2014a). In HvNAS1-overexpressing sweet potato, the Fe and $\mathrm{Zn}$ concentrations increased to 52.9 and $17 \mu \mathrm{g} / \mathrm{g}$ FW in the leaves and 15.1 and $3.5 \mu \mathrm{g} / \mathrm{g} \mathrm{DW}$ in the storage roots, which were 3 and 3, and 2.1 and 3.5 times higher, respectively, than in NT plants (Nozoye et al., 2017). In HvNAS1-overexpressing tobacco, the Fe and $\mathrm{Zn}$ concentrations increased to 5.3 and $9.6 \mu \mathrm{g} / \mathrm{g} \mathrm{FW}$ in the leaves, which were 5 and 2.3 times higher, respectively, than in NT plants (Kim et al., 2005). In HvNAS1-overexpressing rice via the CaMV $35 \mathrm{~S}$ promoter, the $\mathrm{Fe}$ and $\mathrm{Zn}$ concentrations increased to 9 and $45 \mu \mathrm{g} / \mathrm{g}$ DW, respectively, in the polished seeds, which were 2 and 1.5 times higher than in NT seeds (Masuda et al., 2009). In contrast, in HvNAS1-overexpressing rice via the OsActin 1 promoter, the Fe and $\mathrm{Zn}$ concentrations were 170 and $25 \mu \mathrm{g} / \mathrm{g}$ DW in the leaves and 5 and $40 \mu \mathrm{g} / \mathrm{g}$ DW in the polished seeds, respectively, which did not differ significantly from those in NT plants (Masuda et al., 2009). By overexpressing rice NAS genes (OsNAS1-3), the Fe and $\mathrm{Zn}$ concentrations in rice seeds increased to 81 and $91 \mu \mathrm{g} / \mathrm{g} \mathrm{DW}$, respectively, which were 3.5 and 2.2 times higher than in NT seeds (Johnson et al., 2011). In OsNAS1-overexpressing rice via the maize ubiquitin promoter, the $\mathrm{Fe}$ and $\mathrm{Zn}$ concentrations in rice seeds were increased to 28 and $120 \mu \mathrm{g} / \mathrm{g}$ DW, respectively, which were 2.3 and 5.5 times higher than in NT seeds (Zheng et al., 2010). Seed-specific expression of OsNAS1 under control of the rice glutelin promoter, increased the $\mathrm{Zn}$ concentration in rice polished seeds to $29.07 \mu \mathrm{g} / \mathrm{g} \mathrm{DW}$, which was 2.3 times higher than in NT seeds (Zheng et al., 2010); however, the Fe concentration was not altered in the polished seeds. In these plants, the $\mathrm{Fe}$ and $\mathrm{Zn}$ concentrations in leaves were increased to 18 and $30 \mu \mathrm{g} / \mathrm{g}$ DW, which were 1.8 and 1.9 times higher, respectively, than in NT leaves. As with the NA concentration, the $\mathrm{Fe}$ and $\mathrm{Zn}$ concentrations tended to be higher in soybean seeds; however, this difference was not significant compared to the NA concentration. In agreement, the increases in Fe and $\mathrm{Zn}$ concentrations were lower than those of the NA concentration (Table 1). The average increases in $\mathrm{Fe}$ and $\mathrm{Zn}$ were 2.2 and 2.3, respectively, whereas that of NA was 7.6. There might be a factor limiting the increases in the metals compared with NA. Because $\mathrm{Fe}$ and $\mathrm{Zn}$ are taken up from the soil via roots, modification of the uptake system might further increase Fe and $\mathrm{Zn}$. It is also possible that the increased NA in NAS-overexpressing plants was not translocated in the plant body efficiently. There might be potential to increase $\mathrm{Fe}$ and $\mathrm{Zn}$ by changing the flow of NA in the plant body.

\section{NAS-OVEREXPRESSING PLANTS SHOWED TOLERANCE TO Fe DEFICIENCY}

Several NAS-overexpressing plants have been confirmed to tolerate Fe deficiency compared to NT plants (Lee et al., 2009; Nozoye et al., 2014a, 2017). The plant growth is dramatically reduced under Fe-deficient conditions. The plant heights and soil and plant analyzer development (SPAD) values (which represent the chlorophyll content) of NAS-overexpressing soybean and sweet potato plants were higher than those of NT plants when grown in calcareous soil with low Fe availability, suggesting that these transgenic plants were conferred tolerance to Fe deficiency. Under normal soil conditions, their growth did not differ. In rice plants, the Fe-deficiency tolerance of $N A S$-overexpressing rice plants in calcareous soil was not determined. HvNAS1-overexpressing rice exhibits enhanced NAS activity in Fe-deficient roots (Higuchi et al., 2001) and contains a higher amount of NA and deoxymugineic acid than NT plants in both roots and shoots (Masuda et al., 2009). Transgenic rice lines expressing barley NAS genes exhibit increased tolerance to low $\mathrm{Fe}$ availability in calcareous soil (Suzuki et al., 2008). Rice plants overexpressing OsIRO2, a transcription factor that enhances expression of Fe deficiency-inducible genes including OsNAS1 and OsNAS2, showed improved tolerance to low Fe availability in calcareous soil (Ogo et al., 2011). These results suggest that overexpression of the NAS gene in rice also enhances tolerance to $\mathrm{Fe}$ deficiency.

It was recently suggested that NA may be involved in $\mathrm{Fe}$ homeostasis; enhanced NA production induced Fe deficiency signaling and mobilization of $\mathrm{Fe}$ in the plant body (Nozoye et al., 2014b,c). Since NA has the ability to chelate Fe, NA may enable the de-repression of Fe deficiency-inducible genes by drawing Fe from an unknown Fe-sensing mechanism, and further increase the NA and deoxymugineic acid (a primary MAs) levels. NA has long been considered a candidate long-distance Fe signaling molecule in both gramineous and dicot plants (Curie and Briat, 2003); however, this has not yet been proven. In rice, NAS overexpression positively modulates Fe homeostasisrelated genes (Wang et al., 2013). NA accumulation in Osnaat1 mutants triggers a constitutive Fe deficiency response (Cheng et al., 2007). In Arabidopsis, NA-over-accumulating plants showed an Fe-deficient phenotype and expressed Fe-inducible genes at higher levels than did NT plants; however, they also contained more Fe than did NT plants, suggesting that an increase in the NA apoplastic pool sequestered $\mathrm{Fe}$, 
which controls plant Fe homeostasis (Cassin et al., 2009). The overexpression of ZINC-INDUCED FACILITATOR 1 (ZIF1) in Arabidopsis increased the amount of NA in the roots and shoots and led to Fe deficiency (Haydon et al., 2012). ZIF1 is a vacuolar membrane-localized putative transporter required for $\mathrm{Zn}$ tolerance that is hypothesized to transport NA from the cytoplasm into the vacuoles. Perturbing the subcellular distribution of NA may have profound effects on $\mathrm{Fe}$ with respect to subcellular distribution and inter-organ partitioning. In agreement with this phenomenon, it was revealed that AtYSL1 and AtYSL3, Fe-NA transporters, are required for proper longdistance Fe signaling (Kumar et al., 2017). A ysllysl3 doublemutant did not up- or down-regulate Fe deficiency-induced or -repressed genes, while it contained markedly low tissue levels of Fe compared to NT plants. These results suggest that NA may be involved in long-distance signaling to maintain Fe homeostasis. In NAS-overexpressing plants, the increased NA might induce Fedeficiency-inducible genes that contribute to conferring tolerance to Fe deficiency.

\section{CONCLUSION}

Overexpression of the NAS gene enhances NA levels in several crops, including crops in which endogenous NA is already high, such as soybean and sweet potato. Additionally, NAS overexpression enhances the $\mathrm{Fe}$ and $\mathrm{Zn}$ concentrations and confers tolerance to Fe deficiency in calcareous soil. The increase

\section{REFERENCES}

Beneš, I., Schreiber, K., Ripperger, H., and Kircheiss, A. (1983). Metal complex formation by nicotianamine, a possible phytosiderophore. Experientia 39, 261-262. doi: 10.1007/BF01955293

Cassin, G., Mari, S., Curie, C., Briat, J. F., and Czernic, P. (2009). Increased sensitivity to iron deficiency in Arabidopsis thaliana overaccumulating nicotianamine. J. Exp. Bot. 60, 1249-1259. doi: 10.1093/jxb/erp007

Castaings, L., Caquot, A., Loubet, S., and Curie, C. (2016). The high-affinity metal transporters NRAMP1 and IRT1 Team up to take up iron under sufficient metal provision. Sci. Rep. 16:37222. doi: 10.1038/srep37222

Chen, Y., and Barak, P. (1982). Iron nutrition of plants in calcareous soils. $A d v$. Agron. 35, 217-240. doi: 10.1016/S0065-2113(08)60326-0

Cheng, L., Waang, F., Shou, H., Huang, F., Zheng, L., He, F., et al. (2007). Mutation in nicotianamine aminotransferase stimulated the $\mathrm{Fe}$ (II) acquisition system and led to iron accumulation in rice. Plant Physiol. 145, 1647-1657. doi: $10.1104 / p p .107 .107912$

Chirumamilla, R. R., Marchant, R., and Nigam, P. (2001). Captopril and its synthesis from chiral intermediates. J. Chem. Technol. Biotechnol. 76, 123-127. doi: $10.1021 / \mathrm{nn} 2023478$

Conway, G. (2012). One Billion Hungry: Can We Feed the World? London: Cornell University Press, 1-429.

Curie, C., and Briat, J. F. (2003). Iron transport and in plants. Annu. Rev. Plant Biol. 54, 183-206. doi: 10.1146/annurev.arplant.54.031902. 135018

Eide, D., Broderius, M., Fett, J., and Guerinot, M. L. (1996). A novel ironregulated metal transporter from plants identified by functional expression in yeast. Proc. Natl. Acad. Sci. U.S.A. 93, 5624-5628. doi: 10.1073/pnas.93.11. 5624

Haydon, M. J., Kawachi, M., Wirtz, M., Hillmer, S., Hell, R., and Krämer, U. (2012). Vacuolar nicotianamine has critical and distinct roles under iron deficiency and for zinc sequestration in Arabidopsis. Plant Cell 24, 724-737. doi: 10.1105/tpc. 111.095042 in NA tended to be higher in leaves than in seeds, while the increases in $\mathrm{Fe}$ and $\mathrm{Zn}$ were lower than those of NA. These results suggest the potential to increase NA, Fe, and $\mathrm{Zn}$ concentrations further in the edible parts of crops. Further analysis of NA translocation in the plant body will allow for improved engineering strategies not only to accumulate bioavailable $\mathrm{Fe}$ in edible parts, but also to increase the tolerance of plants to low $\mathrm{Fe}$ availability to meet the demands of plant production and to solve problems such as inadequate diet, food shortages, and global warming in the near future.

\section{AUTHOR CONTRIBUTIONS}

TN designed and wrote the manuscript.

\section{FUNDING}

This publication was supported by a grant-in-aid for Young Scientists (B) (Grant No. 15K18658) from JSPS KAKENHI (to $\mathrm{TN}$ ) and by a grant from Uragami-zaidan (to TN).

\section{ACKNOWLEDGMENTS}

I thank Prof. Naoko K. Nishizawa for reading and commenting on the manuscript.

Hell, R., and Stephan, U. W. (2003). Iron uptake, trafficking and homeostasis in plants. Planta 216, 541-551.

Herbik, A., Koch, G., Mock, H. P., Dushkov, D., Czihal, A., Thielmann, J., et al. (1999). Isolation, characterization and cDNA cloning of nicotianamine synthase from barley. A key enzyme for iron homeostasis in plants. Eur. J. Biochem. 265, 231-239. doi: 10.1046/j.1432-1327.1999.00717.x

High Level Expert Forum - How to Feed the World in 2050 (2009). Climate Change and Bioenergy Challenges for Food and Agriculture. Rome: High Level Expert Forum - How to Feed the World.

Higuchi, K., Kanazawa, K., Nishizawa, N. K., and Mori, S. (1996). The role of nicotianamine synthase in response to Fe nutrition status in Gramineae. Plant Soil 178, 171-177. doi: 10.1007/BF00011580

Higuchi, K., Nishizawa, N. K., Yamaguchi, H., Römheld, H., Marschner, H., and Mori, S. (1995). Response of nicotianamine synthase activity to $\mathrm{Fe}$ deficiency in tobacco plants as compared with barley. J. Exp. Bot. 46, 1061-1063. doi: $10.1093 / \mathrm{jxb} / 46.8 .1061$

Higuchi, K., Suzuki, K., Nakanishi, H., Yamaguchi, H., Nishizawa, N. K., and Mori, S. (1999). Cloning of nicotianamine synthase genes, novel genes involved in the biosynthesis of phytosiderophores. Plant Physiol. 119, 471-480. doi: 10.1104/pp.119.2.471

Higuchi, K., Takahashi, M., Nakanishi, H., Kawasaki, S., Nishizawa, N. K., and Mori, S. (2001). Analysis of transgenic rice containing barley nicotianamine synthase gene. Soil Sci. Plant Nutr. 47, 315-322. doi: 10.1080/00380768.2001. 10408395

Hotz, C., and McClafferty, B. (2007). From harvest to health: challenges for developing biofortified staple foods and determining their impact on micronutrient status. Food Nutr. Bull. 28, S271-S279. doi: 10.1177/ 15648265070282 S206

Inoue, H., Higuchi, K., Takahashi, M., Nakanishi, H., Mori, S., and Nishizawa, N. K. (2003). Three rice nicotianamine synthase genes, OsNAS1, OsNAS2, and OsNAS3 are expressed in cells involved in long-distance transport of iron and differentially regulated by iron. Plant J. 36, 366-381. doi: 10.1046/j.1365-313X. 2003.01878.x 
Intergovenmental Panel on Climate Change [IPCC] (2007). "Climate change 2007: synthesis report", Summary for Policymakers. Available at: http://www.ipcc.ch/pdf/assessment-report/ar4/syr/ar4_syr_spm.pdf

Izawa, H., and Aoyagi, Y. (2012). Nicotianamine content among vegetables and their inhibitory activity of angiotensun-I converting enzyme. Nippon Shokuhin Kagaku Kogaku Kaishi. 59, 348-353. doi: 10.3136/nskkk. 59.348

Izawa, H., Yoshida, N., Shiragai, N., and Aoyagi, Y. (2008). Nicotianamine content in various beans and its inhibition activity of angiotensun-I converting enzyme. Nippon Shokuhin Kagaku Kogaku Kaishi. 55, 253-257. doi: 10.3136/nskkk.55. 253

Johnson, A. A., Kyriacou, B., Callahan, D. L., Carruthers, L., Stangoulis, J., Lombi, E., et al. (2011). Constitutive overexpression of the OsNAS gene family reveals single-gene strategies for effective iron- and zinc-biofortification of rice endosperm. PLoS One 6:e24476. doi: 10.1371/journal.pone. 0024476

Kataoka, S. (2005). Functional effects of Japanese style fermented soy sauce (shoyu) and its components. J. Biosci. Bioeng. 100, 227-234. doi: 10.1263/jbb. 100.227

Kawai, S., Kamei, S., Matsuda, Y., Ando, R., Kondo, S., Ishizawa, A., et al. (2001). Concentrations of iron and phytosiderophores in xylem sap of iron-deficient barley plants. Soil Sci. Plant Nutr. 47, 265-272. doi: 10.1080/00380768.2001. 10408390

Kim, S., Takahashi, M., Higuchi, K., Tsunoda, K., Nakanishi, H., Yoshimura, E., et al. (2005). Increased nicotianamine biosynthesis confers enhanced tolerance of high levels of metals, in particular nickel, to plants. Plant Cell Physiol. 46, 1809-1818. doi: 10.1093/pcp/pci196

Kinoshita, E., Yamakoshi, J., and Kikuchi, M. (1993). Purification and identification of an angiotensin I-converting enzyme inhibitor from soy sauce. Biosci. Biotechnol. Biochem. 57, 1107-1110. doi: 10.1271/bbb.57. 1107

Kumar, R. K., Chu, H. H., Abundis, C., Vasques, K., Rodriguez, D. C., Chia, J. C., et al. (2017). Iron-Nicotianamine transporters are required for proper long distance iron signaling. Plant Physiol. 175, 1254-1268. doi: 10.1104/pp.17. 00821

Lee, S., Jeon, U. S., Lee, S. J., Kim, Y. K., Persson, D. P., Husted, S., et al. (2009). Iron fortification of rice seeds through activation of the nicotianamine synthase gene. Proc. Natl. Acad. Sci. U.S.A. 22, 22014-22019. doi: 10.1073/pnas.0910 950106

Marschner, H. (1995). Mineral Nutrition of Higher Plants, Vol. 9, 2nd Edn. London: Academic Press, 313-323.

Marschner, H., Römheld, V., and Kissel, M. (1986). Different strategies in higher plants in mobilization and uptake of iron. J. Plant Nutr. 9, 695-713. doi: 10. 1080/01904168609363475

Masuda, H., Suzuki, M., Morikawa, K., Kobayashi, T., Nakanishi, H., Takahashi, M., et al. (2008). Increase in iron and zinc concentrations in rice grains via the introduction of barley genes involved in phytosiderophore synthesis. Rice 1, 100-108. doi: 10.1007/s12284-008-9007-6

Masuda, H., Usuda, K., Kobayashi, T., Ishimaru, Y., Kakei, T., Takahashi, M., et al. (2009). Overexpression of the barley nicotianamine synthase gene HvNAS1 increases iron and zinc concentration in rice grains. Rice 2, 155-166. doi: 10.1007/s12284-009-9031-1

Mizuno, D., Higuchi, K., Sakamoto, T., Nakanishi, H., Mori, S., and Nishizawa, N. K. (2003). Three nicotianamine synthase genes isolated from maize are differentially regulated by iron nutritional status. Plant Physiol. 132, 1989-1997. doi: 10.1104/pp.102.019869

Mori, S., and Nishizawa, N. (1987). Methionine as a dominant precursor of phytosiderophores in Graminaceae plants. Plant Cell Physiol. 28, 1081-1092.

Mori, S., Nishizawa, N., Hayashi, H., Chino, M., Yoshimura, E., and Ishihara, J. (1991). Why are young rice plants highly susceptible to iron deficiency? Plant Soil 130, 143-156. doi: 10.1007/BF00011869

Murakami, T., Ise, K., Hayakawa, M., Kamei, S., and Takagi, S. (1989). Stabilities of metal complexes of mugineic acids and their specific affinities for iron (III). Chem. Lett. 18, 2137-2140. doi: 10.1246/cl.1989.2137

Noma, M., Noguchi, M., and Tamaki, E. (1971). A new amino acid, nicotianamine, from tobacco leaves. Tetrahedron Lett. 22, 2017-2020. doi: 10.1016/S00404039(01)96769-3
Nozoye, T., Kim, S., Kakei, Y., Takahashi, M., Nakanishi, H., and Nishizawa, N. K. (2014a). Enhanced levels of nicotianamine promote iron accumulation, and tolerance to calcareous soil in soybean. Biosci. Biotechnol. Biochem. 78, 1677-1684. doi: 10.1080/09168451.2014.936350

Nozoye, T., Nagasaka, S., Bashir, K., Takahashi, M., Kobayashi, T., Nakanishi, H., et al. (2014b). Nicotianamine synthase 2 localizes to the vesicles of iron-deficient rice roots, and its mutation in. (the) YXXphi or LL motif causes the disruption of vesicle formation or movement in rice. Plant J. 77, 246-260. doi: 10.1111/tpj. 12383

Nozoye, T., Nagasaka, S., Kobayashi, T., Takahashi, M., Sato, Y., Sato, Y., et al. (2011). Phytosiderophore efflux transporters are crucial for iron acquisition in graminaceous plants. J. Biol. Chem. 286, 5446-5454. doi: 10.1074/jbc.M110. 180026

Nozoye, T., Nakanishi, H., and Nishizawa, N. K. (2013). Characterizing the crucial components of iron homeostasis in the maize mutants ys1 and ys3. PLoS One 8:e62567. doi: 10.1371/journal.pone. 0062567

Nozoye, T., Otani, M., Senoura, T., Nakanishi, H., and Nishizawa, N. K. (2017). Overexpression of barley nicotianamine synthase 1 confers tolerance in the sweet potato to iron deficiency in calcareous soil. Plant Soil 418, 75-88. doi: 10.1007/s11104-016-3134-4

Nozoye, T., Tsunoda, K., Nagasaka, S., Bashir, K., Takahashi, M., Kobayashi, T., et al. (2014c). Rice nicotianamine synthase localizes to particular vesicles for proper function. Plant Signal. Behav. 9:e28660.

Ogo, Y., Itai, R. N., Kobayashi, T., Aung, M. S., Nakanishi, H., and Nishizawa, N. K. (2011). OsIRO2 is responsible for iron utilization in rice and improves growth and yield in calcareous soil. Plant Mol. Biol. 75, 593-605. doi: 10.1007/s11103011-9752-6

Ohrui, T., Tomita, N., Seto-Nakagawa, T., Matsui, T., Maruyama, M., Niwa, K., et al. (2004). Effects of brain-penetrating ACE inhibitors on Alzheimer disease progression. Neurology 63, 1324-1325. doi: 10.1212/01.WNL.0000140705. 23869.E9

Re, R. N. (2004). Mechanisms of disease: local renin-angiotensin-aldosterone systems and the pathogenesis and treatment of cardiovascular disease. Nat. Clin. Pract. Cardiovasc. Med. 1, 42-47.

Robinson, N. J., Procter, C. M., Connolly, E. L., and Guerinot, M. L. (1999). A ferric-chelate reductase for iron uptake from soils. Nature 397, 694-697. doi: $10.1038 / 17800$

Schroeder, J. I., Delhaize, E., Frommer, W. B., Guerinot, M. L., Harrison, M. J., Herrera-Estrella, L., et al. (2013). Using membrane transporters to improve crops for sustainable food production. Nature 497, 60-66. doi: 10.1038/ nature11909

Schuler, M., Rellán-Álvarez, R., Fink-Straube, C., Abadía, J., and Bauer, P. (2012). Nicotianamine functions in the phloem-based transport of iron to sink organs, in pollen development and pollen tube growth in Arabidopsis. Plant Cell 24, 2380-2400. doi: 10.1105/tpc.112.099077

Shojima, S., Nishizawa, N. K., Fushiya, S., Nozoe, S., Irifune, T., and Mori, S. (1990). Biosynthesis of phytosiderophores. In vitro biosynthesis of 2'-deoxymugineic acid from L-methionine and nicotianamine. Plant Physiol. 93, 1497-1503. doi: $10.1104 /$ pp. 93.4 .1497

Shojima, S., Nishizawa, N. K., and Mori, S. (1989). Establishment of a cellfree system for the biosynthesis of nicotianamine. Plant Cell Physiol. 30, 673-677.

Suzuki, K., Higuchi, K., Nakanishi, H., Nishizawa, N. K., and Mori, S. (1999). Cloning of nicotianamine synthase genes from Arabidopsis thaliana. Soil Sci. Plant Nutr. 45, 993-1002. doi: 10.1080/00380768.1999.1041 4350

Suzuki, M., Morikawa, K. C., Nakanishi, H., Takahashi, M., Saigusa, M., Mori, S., et al. (2008). Transgenic rice lines that include barley genes have increased tolerance to low iron availability in a calcareous paddy soil. Soil Sci. Plant Nutr. 54, 77-85. doi: 10.1111/j.1747-0765.2007.00205.x

Suzuki, M., Takahashi, M., Tsukamoto, T., Watanabe, S., Matsuhashi, S., Yazaki, J., et al. (2006). Biosynthesis and secretion of mugineic acid family phytosiderophores in zinc-deficient barley. Plant J. 48, 85-97. doi: 10.1111/j. 1365-313X.2006.02853.x

Takada, N. (2011). Memory improvement effect of nicotianamine and its ACE inhibitory mechanism. Rep. Uragamizaidan 18, 24-30.

Takagi, S. (1976). Naturally occurring iron-chelating compounds in oat-and rice-root washings : I. Activity measurement and preliminary characterization. 
Soil Sci. Plant Nutr. 22, 423-433. doi: 10.1080/00380768.1976.1043 3004

Takahashi, M., Terada, Y., Nakai, I., Nakanishi, H., Yoshimura, E., Mori, S., et al. (2003). Role of nicotianamine in the intracellular delivery of metals and plant reproductive development. Plant Cell 15, 1263-1280.

Vert, G., Grotz, N., Dédaldéchamp, F., Gaymard, F., Guerinot, M. L., Briat, J.F., et al. (2002). IRT1, an Arabidopsis transporter essential for iron uptake from the soil and for plant growth. Plant Cell 14, 1223-1233. doi: 10.1105/tpc. 001388

von Wirén, N., Klair, S., Bansal, S., Briat, J.-F., Khodr, H., Shioiri, T., et al. (1999). Nicotianamine chelates both FeIII and FeII. Implications for metal transport in plants. Plant Physiol. 119, 1107-1114. doi: 10.1104/pp.119.3. 1107

Wang, M., Gruissem, W., and Bhullar, N. K. (2013). Nicotianamine synthase overexpression positively modulates iron homeostasis-related genes in high iron rice. Front. Plant Sci. 4:156. doi: 10.3389/fpls.2013. 00156
Welch, R. M., and Graham, R. D. (2004). Breeding for micronutrients in staple food crops from a human nutrition perspective. J. Exp. Bot. 55, 353-364. doi: $10.1093 /$ jxb/erh064

Zheng, L., Cheng, Z., Ai, C., Jiang, X., Bei, X., Zheng, Y., et al. (2010). Nicotianamine, a novel enhancer of rice iron bioavailability to humans. PLoS One 5:e10190. doi: 10.1371/journal.pone.0010190

Conflict of Interest Statement: The author declares that the research was conducted in the absence of any commercial or financial relationships that could be construed as a potential conflict of interest.

Copyright (C) 2018 Nozoye. This is an open-access article distributed under the terms of the Creative Commons Attribution License (CC BY). The use, distribution or reproduction in other forums is permitted, provided the original author $(s)$ and the copyright owner are credited and that the original publication in this journal is cited, in accordance with accepted academic practice. No use, distribution or reproduction is permitted which does not comply with these terms. 